\title{
An Unusual Foreign Body in the Nasal Cavity
}

\author{
Rameshbabu Kalyanasundaram, Ramanathan Thirunavukkarasu, \\ Ganeshkumar Balasubramaniam, Hemalatha Palaniappan \\ Department of ENT, Thanjavur Medical College, Thanjavur, India \\ Email: k.rameshbabu.ent@gmail.com
}

Received 24 June 2014; revised 23 July 2014; accepted 22 August 2014

Copyright (C) 2014 by authors and Scientific Research Publishing Inc.

This work is licensed under the Creative Commons Attribution International License (CC BY). http://creativecommons.org/licenses/by/4.0/

c. (i) Open Access

\begin{abstract}
The nasal foreign bodies are commonly seen up to the age of 12. This is a rare case of a 10-year-old boy who had playfully introduced an almost straight sharp rigid iron wire of length $13 \mathrm{~cm}$ into his nose. The patient presented with the foreign body protruding outside his nose. Radiological investigations revealed that the foreign body had hooked around the posterior end of the bony septum which was removed under endoscopic guidance.
\end{abstract}

\section{Keywords}

Foreign Body, Iron Wire in Nose, Nasal Cavity, Epistaxis

\section{Introduction}

Foreign bodies in the ear nose throat are common in the emergency department [1]. The nasal foreign bodies stand next to most common to the ear [2] with a slight male preponderance [3] about 58.97\%. According to Chiun et al., the incidence of ear foreign bodies is the highest, about 44.3\%, followed by nose (24.9\%), pharynx (23.2\%), oesophagus (5.3\%), airway (2.3\%). According to Jonathan et al., the nasal foreign bodies are common in paediatric age group and can affect adults with psychiatric illness and mental retardation. Most of the foreign bodies in the nose are asymptomatic [4]. Children commonly introduce foreign bodies in order to explore their bodies and also to relieve irritation [1]. We present an interesting case of a 10-year-old male child with a sharp iron wire protruding from his left nostril.

\section{Case Report}

A 10-year-old boy reported to our hospital with an almost straight sharp iron wire with a looped end of size 13 cm inserted into his left nostril (Figure 1). History revealed that the patient himself voluntarily inserted the foreign body for fun which got struck into the nasal cavity. The parents rushed with the child to the nearby medical practitioner where the attempt was made for the foreign body removal under direct vision was unsuccessful.

How to cite this paper: Kalyanasundaram, R., Thirunavukkarasu, R., Balasubramaniam, G. and Palaniappan, H. (2014) An Unusual Foreign Body in the Nasal Cavity. International Journal of Otolaryngology and Head \& Neck Surgery, 3, $267-270$. http://dx.doi.org/10.4236/ijohns.2014.35049 
The past history revealed there was a similar incidence at the age of 6 years. The patient had introduced a foreign body in his left ear for which he was hospitalized for foreign body removal .The family history revealed that the parents were having literacy up to the primary school level with poor socioeconomic status. Routine blood investigations were within normal limits. The X-ray skull lateral view (Figure 2), X-ray water's view, and CT paranasal sinuses (Figure 3) pointed out that it was a looped iron wire where the looped end had pierced the lower part of posterior end of the septum and protruded into the opposite choana.

The patient was shifted to the emergency operation theatre with the premedication of atropine and anterior nasal packing with $4 \%$ lignocaine with xylometazoline [LA]. Using $0^{\circ} 2.7 \mathrm{~mm}$ Hopkins rod, the foreign body was visualized and it was found along the floor of the nasal cavity piercing the posterior end of bony septum. The adjoining area of the septum was edematous with minimal bleeding and so the endoscope was introduced into the right nasal cavity to visualize the pierced end, where the foreign body was pushed backwards and posteriorly in order to release it from the anchored tissues and was pushed into the left nasal cavity where it was previously inserted by the patient and then it was removed successfully with very minimal manipulations (Figure 4). Post operatively the patient was given intravenous antibiotics and anterior nasal packing was done which was removed after 2 hours. The patient was given saline nasal wash to remove the iron rusts and to prevent synechiae. $3 \%$ saline nasal drops were given to reduce edema. With all the above measure the postoperative period was uneventful. The patient was sent to the psychiatrist who suggested for counseling and he was discharged.

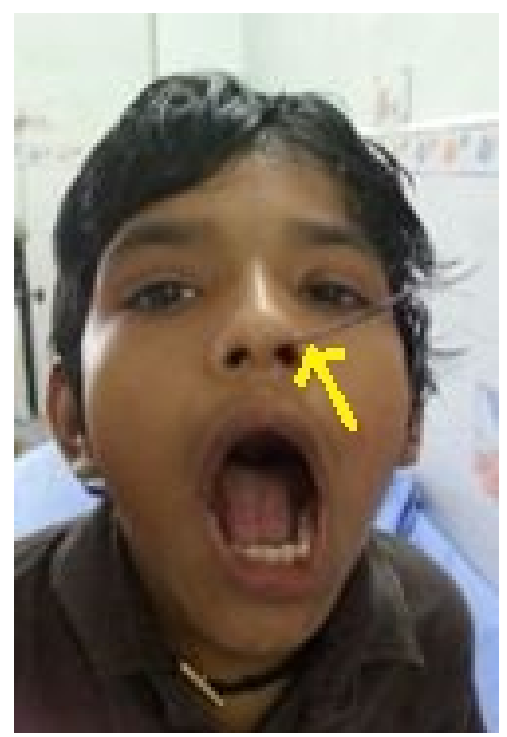

Figure 1. The photo of patient showing iron wire in left nostril.

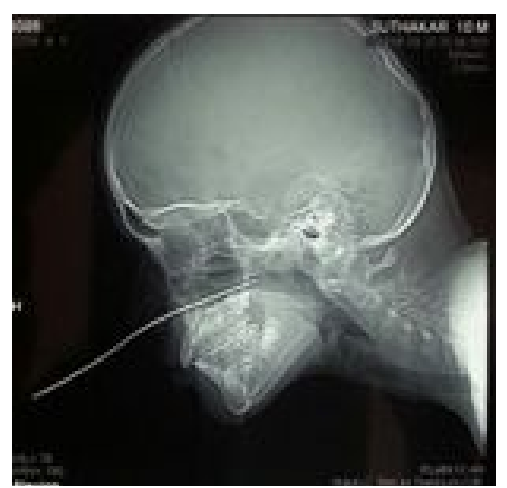

Figure 2. X-ray skull lateral view showing iron wire in nasal cavity. 


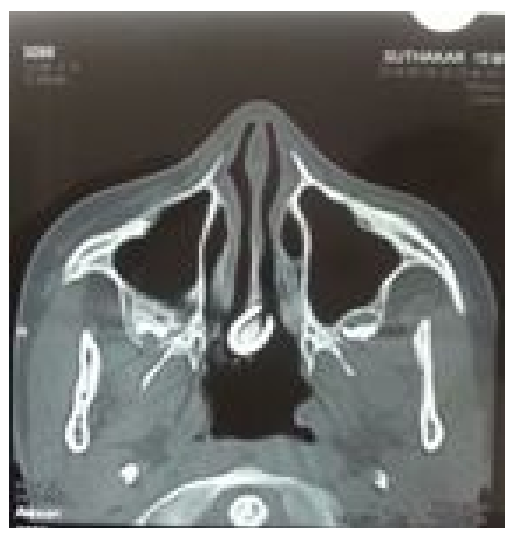

Figure 3. CT scan showing iron wire piercing posterior end of septum and protruding into opposite side.

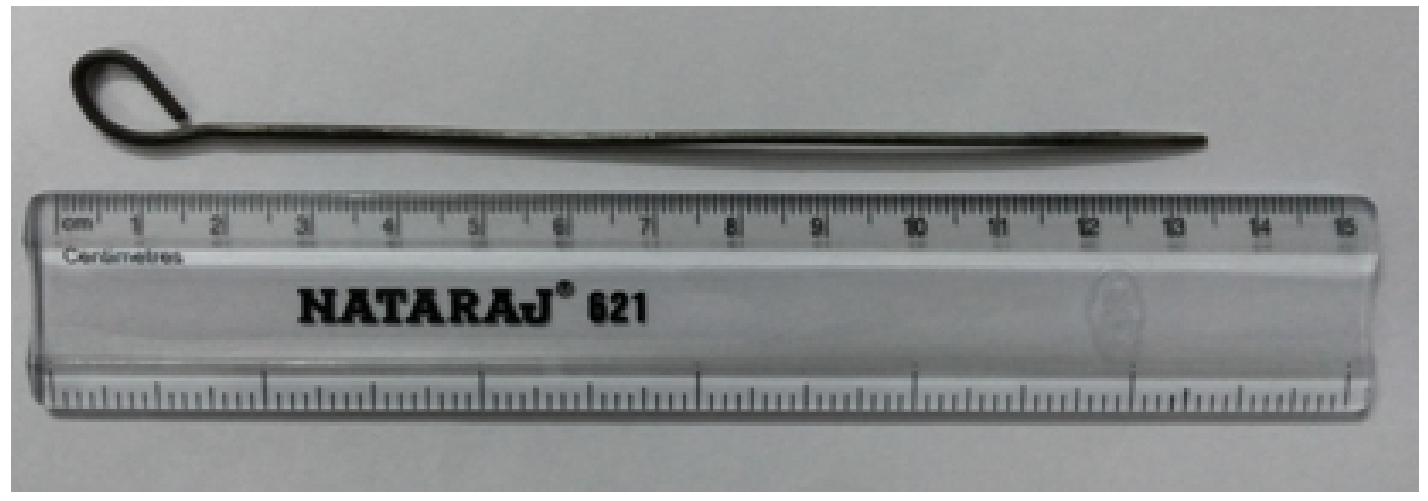

Figure 4. Picture of the iron wire after removal.

\section{Discussion}

Foreign bodies are common in ENT practice and it accounts for about $11 \%$ of ENT cases and complications may occur in about 22\% of such cases [5]. The nasal foreign bodies are exclusively limited up to the age of 12 [6] (the patient discussed here is 10 years old). They are also seen in adults especially those with mental retardation. Even though the nasal foreign body removal appears to be simple procedure, it produces potential morbidity due to mucosal damage and mortality due to dislodgement into the airway. The most common sites of impaction of nasal foreign body are inferior turbinate, middle turbinate, sphenoid sinus, superior turbinate respectively [1]. But in our case it got penetrated into the lower part of posterior bony septum in the opposite side. The foreign bodies are common among the children with poor socioeconomic status and illiterate parents (35.1\%) or literacy up to primary level (21.12\%) [3]. 22.2\% of such children has similar incidence in the past [7]. Most of the foreign bodies are asymptomatic [4]. The local inflammation and pressure necrosis can cause mucosal ulceration and erosion into the blood vessels to produce minimal epistaxis. The patient can go for sinusitis, nasal septal perforation, meningitis, tetanus and diphtheria as complication [1]. The CT paranasalsinuses remains the gold standard investigation of choice in nasal foreign body [8]. The foreign body removal should be attempted by experts only as repeated attempts may result in increased morbidity and mortality. Hence careful planning with necessary instruments is mandatory for successful foreign body removal [1] [5]. The procedure should be necessarily done in the operation theatre to in order to handle the untoward complications during removal [9]. Local anesthesia with proper premedication and local vasoconstriction aids in better visualization by reducing mucosal edema. The patient position depends upon the type of foreign body.

\section{Conclusions}

- The sharp penetrating foreign bodies should be carefully handled and have to be attempted by the experts 
with proper instruments.

- Most of the sharp penetrating intranasal foreign bodies require surgical intervention.

The CT scan remains the investigation of choice for inorganic foreign bodies in locating the site of impaction better than $\mathrm{X}$-rays.

\section{References}

[1] Fisher J.L. (2013) Nasal Foreign Bodies—Medscape References Updated. Medscape.

[2] Chiun, K.C., Tang, I.P., Tan, T.Y. and Jong, D.E. (2012) Review of Ear, Nose and Throat Foreign Bodies in Sarawak General Hospital. A Five-Year Experience. Medical Journal of Malaysia, 67, 17-20.

[3] Shrestha, I., Shrestha, B.L. and Amatya, R.C. (2012) Analysis of Ear, Nose and Throat Foreign Bodies in Dhulikel Hospital. Kathmandu University Medical Journal (KUMJ), 10, 4-8.

[4] Kelesidis, T., Osman, S. and Dinerman, H. (2010) An Unusual Foreign Body as Cause of Chronic Sinusitis: A Case Report. Journal of Medical Case Report, 4, 157. http://www.jmedicalcasereports.com/content/4/1/157

[5] Mangussi-Gomes, J., de Andrade, J.S., Matos, R.C., Kosugi, E.M. and Penido Nde, O. (2013) ENT Foreign Bodies: Profile of Cases Seen at Teritiary Hospital Emergency Unit. Brazilian Journal of Otorhinolaryngology, 79, 699-703.

[6] Endican, S., et al. (2006) Ear Nose and Throat Foreign Bodies in Melanessan Children an Analysis of 1037 Cases. International Journal of Pediatric Otorhinolaryngology, 70, 1539-1545.

[7] Mukherjee, A., Haldar, D., Dutta, S., Dutta, M., Saha, J. and Sinha, R. (2011) Ear Nose and Throat Foreign Bodies in Children: A Search for Socio Demographic Correlates. International Journal of Pediatric Otorhinolaryngology, 75, 510-512.

[8] Dissenha, Luis, J., Stramandinoli, T., et al. (2011) Medicinia Dentaria Cirurgia Maxilofacial, Janeiro. Revista Portuguesa de Estomatologia, 52, 39-42.

[9] Street, I. (2009) Infection and Foreign in the Ear, Nose and Throat. Surgery Journal, 27, 518-512. 
Scientific Research Publishing (SCIRP) is one of the largest Open Access journal publishers. It is currently publishing more than 200 open access, online, peer-reviewed journals covering a wide range of academic disciplines. SCIRP serves the worldwide academic communities and contributes to the progress and application of science with its publication.

Other selected journals from SCIRP are listed as below. Submit your manuscript to us via either submit@scirp.org or Online Submission Portal.
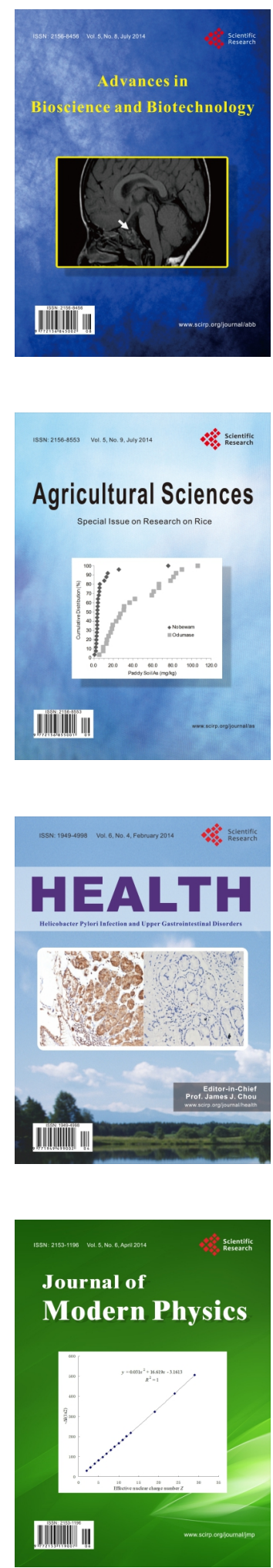
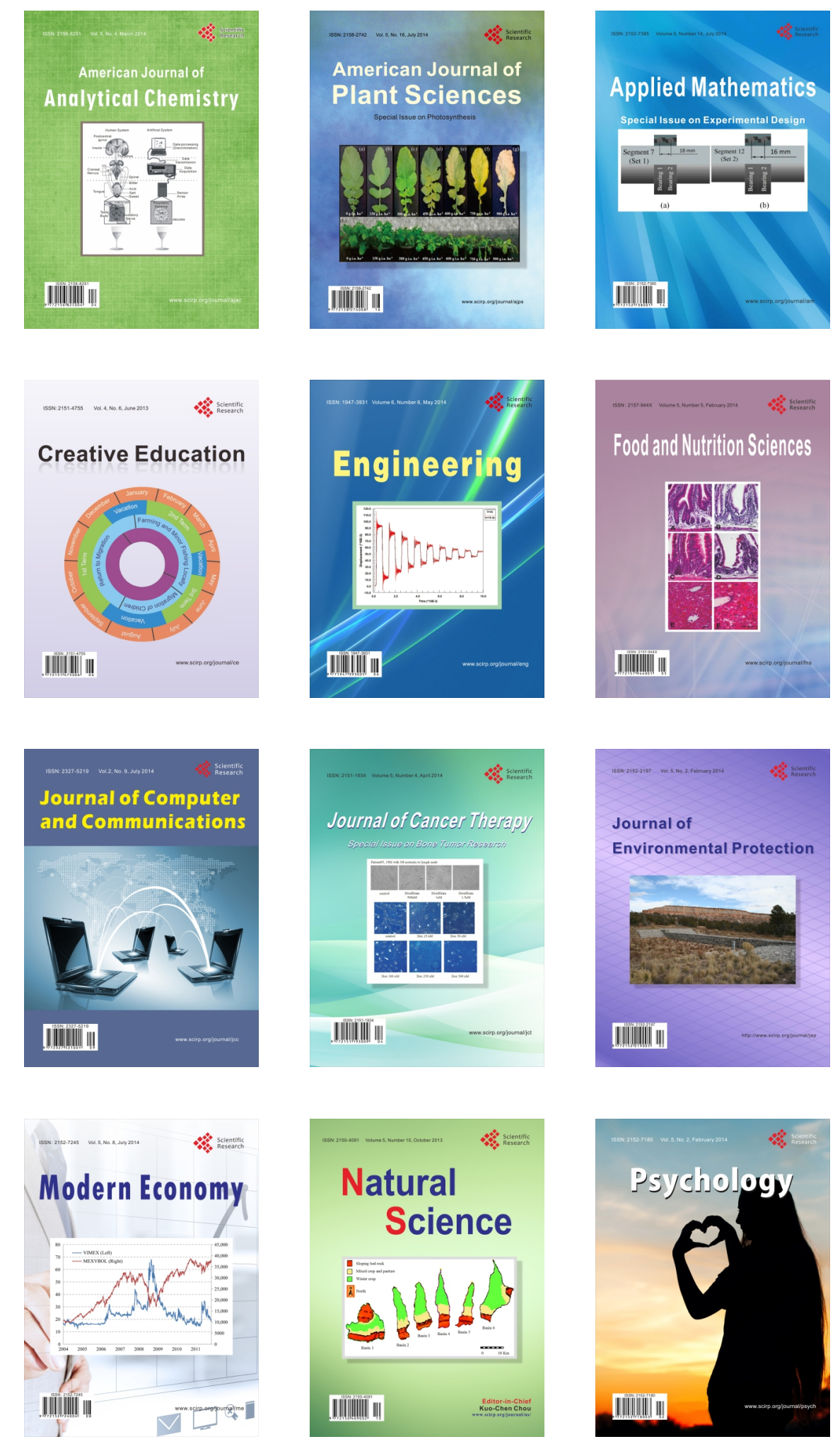